\title{
Impact of bronchodilator therapy on exercise tolerance in COPD
}

This article was published in the following Dove Press journal:

International Journal of COPD

5 March 2010

Number of times this article has been viewed

\author{
B Aguilaniu \\ HYLAB, Laboratory of Clinical \\ Physiology and Exercise, \\ Grenoble, France
}

Correspondence: B Aguilaniu HYLAB, Clinical Physiology and Exercise, CHU A. Michallon, BP I85, 38042, Cedex 09, Grenoble, France Tel +330476291770 Fax +330476338469 Email b.aguilaniu@wanadoo.fr

\begin{abstract}
Exercise tolerance is an important parameter in patients with COPD and a primary goal of treatment is to reduce dyspnea to facilitate physical activities and improve health-related quality of life. This review examines the link between expiratory flow limitation and dyspnea to explain the rationale for the use of bronchodilators and review the characteristics of different types of exercise tests, with specific focus on which tests are likely to show a response to bronchodilators. An earlier literature search of studies published up to 1999 assessed the effects of bronchodilator therapy on dypsnea and exercise tolerance among patients with COPD. This current review examines the clinical evidence published since 1999. Thirty-one randomized studies of exercise tolerance associated with short- and long-acting $\beta_{2}$-agonists and anticholinergics were identified. Evidence for the efficacy of bronchodilators in enhancing exercise capacity is often contradictory and possibly depends on the exercise test and study methodology. However, further studies should confirm the benefit of long-acting bronchodilators in improving spontaneous everyday physical activities.
\end{abstract}

Keywords: COPD, exercise, bronchodilator, walk test, exercise test

\section{Introduction}

Chronic obstructive pulmonary disease (COPD) is a substantial healthcare burden worldwide. ${ }^{1}$ In developed countries, COPD is already a leading cause of death (ranked fourth in the US) and its prevalence is predicted to increase. ${ }^{2}$ In addition, the number of smokers is rising in many countries (notably among women), leading to an escalating prevalence of COPD. ${ }^{3,4}$

COPD is characterized by dyspnea-induced impairment that can significantly impair performance of everyday tasks. Hence, a primary goal in the management of COPD is to improve dyspnea to facilitate physical activities and, ideally, should be obtained whatever the severity of the disease to improve the patient's health-related quality of life (HRQoL).

Exercise testing is an increasingly used outcome measure in assessing COPD treatments in lieu of the ability to measure improvement in physical activity itself. Indeed, physical activity in COPD or aging patients is correlated with maximal exercise capacity determined by an incremental cycle exercise test. Moreover, poor exercise capacity in COPD patients is a predictor of mortality, ${ }^{5,6}$ and hence would be a useful measure during clinical practice, though most methods for measuring exercise capacity are appropriate for the laboratory. Another important finding from laboratory exercise testing is determining the locus of limiting symptom in poor exercise capacity, which 
is frequently, but not exclusively, due to dyspnea ${ }^{7,8}$; however, many patients also show a degree of muscle fatigue that highlights the importance of conditioning through exercise for patients with COPD.

Bronchodilation is a key therapy in COPD, aimed at alleviating bronchial obstruction and airflow limitation. Guidelines recommend bronchodilators as first-line maintenance therapy for patients with all severities of disease..$^{9,10}$ Yet, despite the efficacy of bronchodilators in improving both bronchial obstruction and pulmonary distension at rest, evidence for their beneficial effect on exercise capacity is inconsistent. ${ }^{11,12}$ In a systematic review on the effects of bronchodilators on exercise capacity, Liesker et $\mathrm{al}^{11}$ reported that a significant improvement in exercise tolerance was observed in only half of the studies. Since 1999, numerous additional studies have investigated the effects of bronchodilators on exercise capacity, including studies with once-daily bronchodilators, such as the anticholinergic tiotropium and the $\beta_{2}$-agonist indacaterol, which had not previously been reviewed. In addition, there have been some advances in our understanding of the mechanisms by which bronchodilators can improve exercise capacity and tolerance, and which exercise tests are likely to show a response to bronchodilators.

This review aims to examine the clinical evidence published since 1999 on the effect of bronchodilators on exercise tolerance among patients with COPD, and to review the characteristics and clinical significance of exercise tests. First, the link between expiratory flow limitation and dyspnea is examined to explain the rationale for using bronchodilators and the advantages of improved airflow in relation to exercise tolerance.

\section{Selection of studies for review}

Literature on the impact of short- and long-acting bronchodialtors on exercise tolerance in patients with COPD was reviewed by performing a PubMed database search, using the search terms "exercise", "COPD”, "pulmonary disease" and the drug scientific name. The search was limited to articles published in English between 1999 and 2009, reporting on studies of adult ( $\geq 19$ years) patients. Studies in asthma were excluded. A total of 14 studies of short-acting bronchodilators (salbutamol, procaterol, ipratropium and oxitropium) and 22 studies of long-acting bronchodilators (salmeterol, formoterol and tiotropium) were identified. At the time of writing, no published studies with indacaterol were found to include exercise testing.

\section{Air trapping and exercise pulmonary hyperinflation - the link from expiratory flow limitation to daily-living dyspnea}

Expiratory flow limitation (EFL) is the primary physiological hallmark of COPD, and the most prominent and distressing symptom is dyspnea. The relationship between EFL and the ability to perform day-to-day activities is complex; for example, forced expiratory volume in 1 second $\left(\mathrm{FEV}_{1}\right)$ is important for the diagnosis and monitoring of COPD, ${ }^{6}$ but clinically relevant improvements in symptoms can occur in the absence of significant changes in $\mathrm{FEV}_{1}$, and vice versa. ${ }^{13,14}$

A physiological link between EFL and patient-centered outcomes may be air trapping and resultant hyperinflation. Spirometric indices of hyperinflation, such as inspiratory capacity (IC), correlate more closely with improvements in dyspnea and exercise tolerance than changes in $\mathrm{FEV}_{1}{ }^{13-15}$ Hence, air trapping resulting from EFL, rather than EFL per se, may be the significant contributor to dyspnea and exercise limitation in COPD. ${ }^{16,17}$

Air trapping can occur due to both static and dynamic hyperinflation processes. Static air trapping can occur due to the emphysema and other structural changes in the lung that causes the lung to be capable of expelling less air. Dynamic air trapping additionally occurs when there is insufficient expiratory time for adequate lung emptying. As a result, the volume of air left in the lung at the end of expiration is increased and the IC is decreased. It is dynamic hyperinflation that is susceptible to manipulation with bronchodilator treatment. This process of dynamic air trapping is exacerbated during more rapid rates of ventilation, such as that which occurs during exercise. In COPD patients with a severe EFL, dynamic air trapping may even occur at a resting respiratory rate. Air trapping may occur gradually or abruptly, depending on the severity of EFL and the intensity of the exercise, which can affect exercise endurance. For example, if air trapping progresses gradually relative to the ventilation rate, patients will endure the ensuing dyspnea and exercise for longer than if it occurs abruptly. This suggests that air trapping is the primary functional limitation on exercise tolerance. ${ }^{16}$ Further support for this hypothesis is provided by the fact that improvements in dynamic air trapping correlate highly with reductions in dyspnea. ${ }^{18}$

Activity limitation is accelerated through a vicious circle that develops as the gradual decline of lung function causes 
dynamic air trapping, which triggers a reduction in exercise tolerance due to dyspnea and muscle fatigue. ${ }^{16,19}$ Dyspnea dictates the level of activity undertaken and may discourage some patients from participating in physical activities. ${ }^{20,21}$ Chronic inactivity results in more rapid muscle fatigue due to deconditioning, leading to worsening of disease and further deterioration of the patient's HRQoL. ${ }^{22}$ Thus, the alleviation of exercise dyspnea by the reduction of dynamic air trapping and hyperinflation remains the principal goal of treatment.

\section{Clinical exercise testing}

Since dyspnea is the primary cause of impaired daily-living activities in patients with COPD, it is important to evaluate exercise tolerance using clinical testing to determine the patient's level of incapacity and response to treatment. There are several types of structured clinical exercise tests ranging from the simple and inexpensive self-paced 6-minute or 12-minute walk distance (6MWD/12MWD) test and externally-paced shuttle walk test (SWT), to the sophisticated and expensive cardiopulmonary exercise test.

The protocols used for exercise tests can be classified as constant work rate (CWR) or incremental. In the former, the work rate is virtually constant throughout the test; hence, the duration of the test can be relatively long compared with incremental workload tests, in which the workload is increased to volitional exhaustion and maximal or near maximal aerobic capacity.

Cardiopulmonary exercise testing (CPET) provides the most complete physiological evaluation, including insights into the mechanisms of exercise limitation ${ }^{23}$; however, the equipment is expensive and requires regular maintenance and calibration. Furthermore, qualified personnel are needed to supervise the tests to ensure patient safety.

CPET can be used with both incremental and CWR protocols and permits the evaluation of submaximal and peak exercise responses. Modes of exercise most commonly used are the treadmill and cycle ergometer. In respiratory clinical tests, the cycle ergometer is often preferred as it offers direct quantification of the work rate, the static upper body allows easier collection of blood samples and fewer artifacts on the electrocardiogram, and it is often cheaper and safer. ${ }^{24}$ A limitation is that local muscle fatigue is more predominant with cycle ergometry compared with walking on a treadmill. ${ }^{7,12,25}$ A meta-analysis of clinical trials of respiratory rehabilitation in patients with COPD determined a minimum clinical important difference (MCID) of $8.3 \mathrm{~W}$ (95\% CI, 2.8-16.5) maximum exercise capacity using incremental or progressive cycle ergometry (PCE) ${ }^{26}$ Recently, the MCID for CWR on a cycle ergometer has been suggested to be an increase in exercise time of approximately $33 \%$ of baseline, though further validation is required. ${ }^{27} \mathrm{~A}$ literature search revealed no studies that have determined the MCIDs for treadmill CPET.

Flat-course walk-tests are the easiest and most economical procedures for evaluating exercise capacity, as no specialist equipment is required; however, results are dependent on the motivation of the patient and the degree of encouragement offered. In addition, there exists some uncertainty about the interpretation of results, particularly with respect to the MCID. $^{28}$

The 6MWD test differs from the other tests in that it is self-paced and dependent on patient characteristics and methodology. The American Thoracic Society has developed guidelines to standardize the use of the 6MWD test in clinical settings, in particular for the measurement of outcomes before and after treatment, ${ }^{29}$ and an improvement of $\geq 54 \mathrm{~m}$ has been proposed as being clinically important in patients with stable COPD. ${ }^{30} \mathrm{~A}$ more recent analysis estimated that the 6MWD should change by approximately $35 \mathrm{~m}$ (or $10 \%$ from baseline) for patients with moderate-to-severe COPD in order to represent a clinically important effect. ${ }^{28}$ These discrepancies in MCID may reflect the variable nature of the walk tests but also highlight the need to consider disease severity when interpreting treatment changes.

Recent reviews of published studies suggest that the 6MWD test is less sensitive in discerning an effect of bronchodilators than cycle ergometery, though there are correlations in results between the two tests in general. A number of factors have been suggested to account for this difference, including the short duration of the self-paced, non-maximal exercise and the variability between patients. The 6MWD test also has a lower correlation to lung function than cycle ergometry CPET. Nevertheless, changes in exercise endurance with non-pharmacological interventions have been discernable using the 6MWD.

The SWT was designed to overcome the criticism that patients are unlikely to extend themselves during self-paced timed-walk tests. ${ }^{31}$ The technique allows objective measurement of subjective performance and reduces the effects that frailty and comorbidity may have in elderly patients. The test comprises a $10 \mathrm{~m}$ course, externally paced by an audiotape, which increases at set intervals until volitional exhaustion. The SWT is standardized and both incremental and CWR exercise tests can be performed.

The outcome parameter for the incremental SWT is the distance covered before the patient stops because of dyspnea 
or muscle fatigue and the MCID for the incremental SWT has recently been defined as $47.5 \mathrm{~m} .{ }^{32}$ Even though the incremental SWT is not an endurance test and is arguably less relevant to paced activities of daily living, results do correlate with the $6 \mathrm{MWD}$. As with the $6 \mathrm{MWD}$, the correlation between the incremental SWT and lung function is low, but changes in dyspnea have greater similarity to incremental CPET than to the 6MWD.

The endurance SWT is of considerable interest following recent work demonstrating that this CWR test is sufficiently sensitive to detect changes with inhaled bronchodilators. ${ }^{7}$ Indeed, exercise endurance time with the SWT may be more sensitive to change from bronchodilators than cycle ergometry, though the reasons for this are unclear. The constant walking speed for the endurance SWT is calculated as $85 \%$ of the maximum sustainable walking speed from the incremental SWT. Endurance SWT correlates with treadmill testing, though the actual endurance times are shorter with SWT and there is no MCID established for the endurance SWT.

The performance-based tests described above, although providing reliable estimates of exercise capacity, may not be suited for primary care due to cost and time constraints. In addition, it remains uncertain whether such tests accurately reflect performance of daily activities such as stairclimbing. ${ }^{33}$ Other tests used to evaluate functional ability and exertion-induced dypsnea include unsupported arm exercise tests, such as the sit-to-stand test, step testing and Glittre activity daily living [ADL] test. ${ }^{34-38}$ These tests evaluate daily-living activities such as climbing stairs, lifting and carrying, bending down and rising from a seated position, and are beneficial in that they are less time-consuming, easy to implement in the primary care environment, and complement conventional exercise tests such as the 6MWD. However, additional studies are required to evaluate their validity and reproducibility.

\section{Impact of bronchodilators on exercise tolerance}

Inhaled $\beta_{2}$-agonists and anticholinergics currently form the main classes of bronchodilators used in the treatment of COPD. Although oral theophyllines are still used, the findings of clinical studies suggest that they have little or no effect on exercise capacity. ${ }^{11}$ Moreover, there have been no new exercise studies with theophylline since 1999.

The database search identified 31 double-blind, typically placebo-controlled studies published since 1999 that included monotherapy with a bronchodilator (Tables 1 and 2). These studies are discussed below. When interpreting the data, it is important to remember the limitations of comparison between the different methodologies and patient populations.

\section{Short-acting bronchodilators (Table I) \\ Short-acting $\beta_{2}$-agonists}

Several salbutamol studies were performed before 2000 and are reviewed in detail by Liesker, 2002.1 ${ }^{11}$ In brief, seven studies assessing the effect of salbutamol on exercise endurance (using the 6MWD or 12MWD) were reviewed ${ }^{39-45}$ and a significant improvement in endurance, compared with placebo, was observed in all but one of the studies. Only one of the two 6MWD trials could be assessed for MCID, ${ }^{43}$ but this would achieve MCID according to the $\geq 35 \mathrm{~m}$ criteria proposed by Puhan and colleagues, ${ }^{28}$ but not according to the $\geq 54$ m criteria of Redelmeier and colleagues. ${ }^{30}$

Since 1999, the impact of the short-acting $\beta_{2}$-agonist, salbutamol, has been determined in three studies: two using cardiopulmonary exercise tests and one using upper limb exercises (Table 1). ${ }^{46-48}$ In each of these studies, salbutamol was administered as a single dose, reflecting the fact that its most appropriate use is as rescue medication. ${ }^{49}$

In the two studies using cardiopulmonary tests, ${ }^{46,47}$ endurance was assessed by CWR cycle exercise. A significant increase in endurance time was observed by Oga et $a,^{5}$ though this was short of being clinically significant according to the criteria of Puente-Maestu and colleagues. Aliverti et $\mathrm{al}^{47}$ observed no change in CWR cycling exercise endurance time with salbutamol despite a significant decrease in IC, suggesting that salbutamol was efficacious in avoiding dynamic hyperinflation during the exercise, but this did not affect endurance time. In the study by Porto et $\mathrm{al},{ }^{48}$ a significant decrease in IC was observed after performing an incremental arm exercise test following inhalation with placebo; however, no change was observed following inhalation with salbutamol, suggesting again that the bronchodilator prevented hyperinflation development.

More recently, two studies ${ }^{50,51}$ have evaluated the impact of procaterol on exercise performance. Shioya et $\mathrm{al}^{50} \mathrm{dem}-$ onstrated clinically significant improvements in walking distance using the 6MWD (42 m, $P<0.05)$ together with significant improvements in dysnpea and $\mathrm{FEV}_{1}$. In the study by Sukisaki and colleagues, ${ }^{51}$ statistically significant improvements in the incremental SWT (37 m, $P<0.001)$ were reported, despite no significant improvements in $\mathrm{FEV}_{1}$, though this distance is below the MCID. 


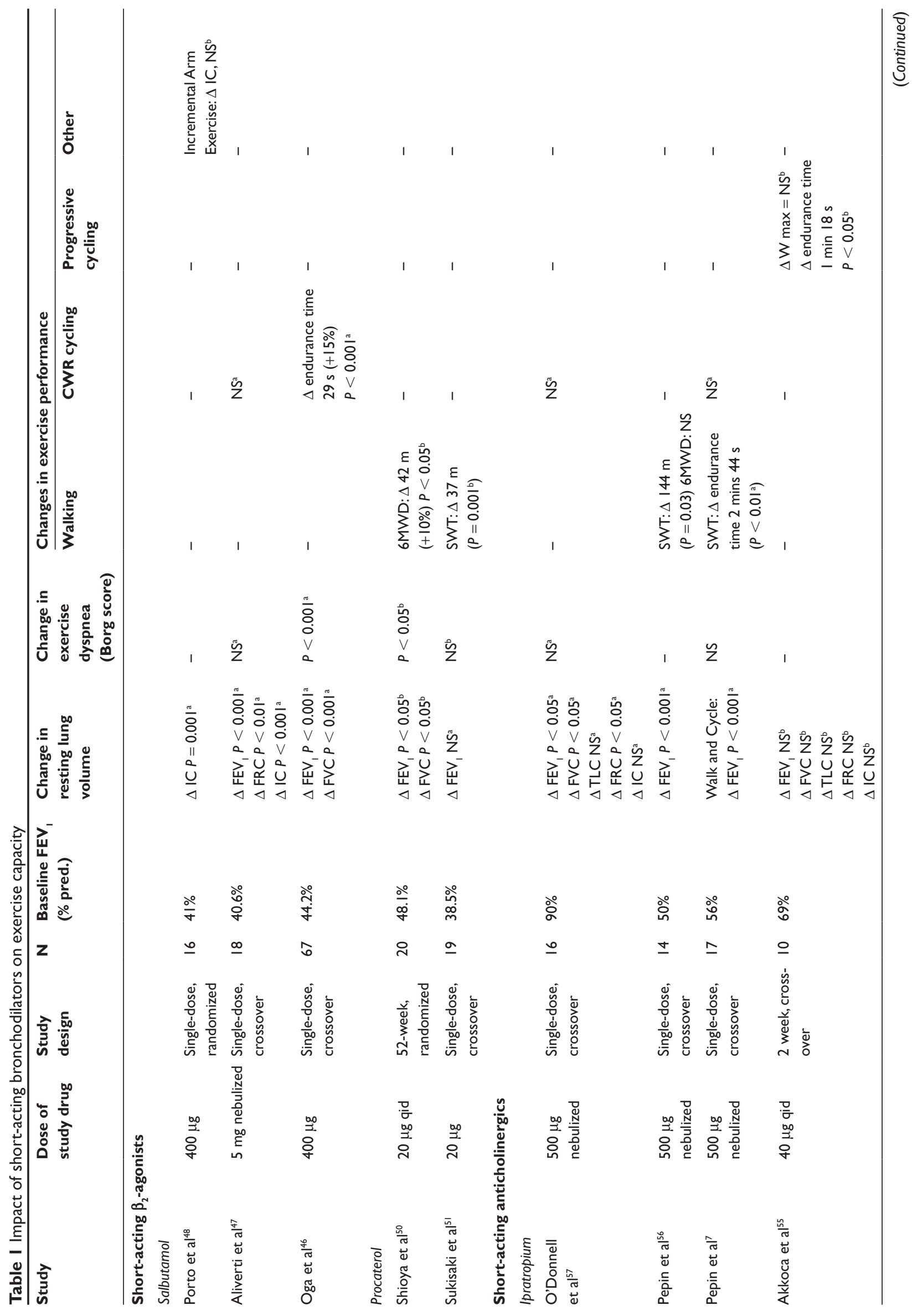




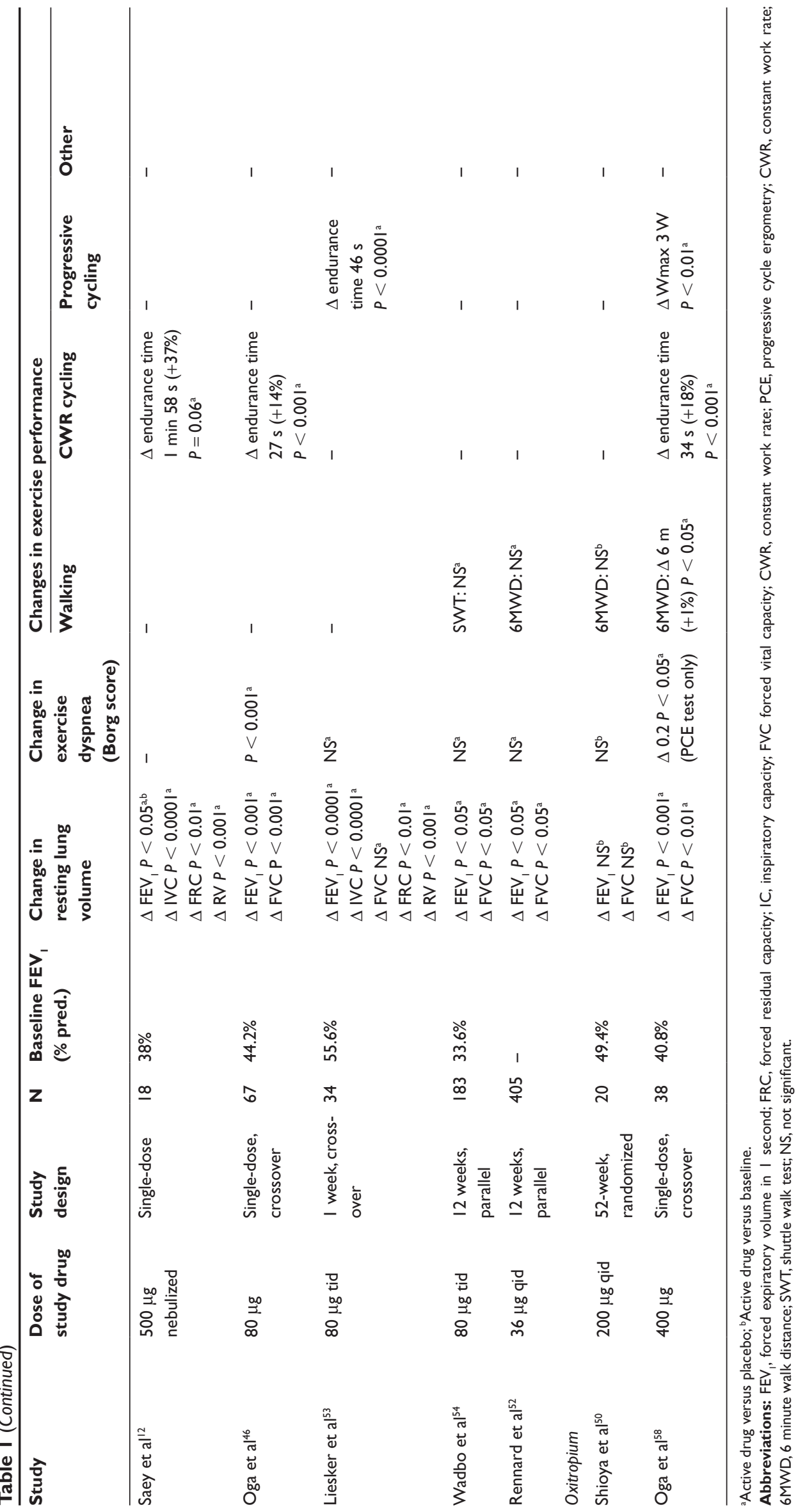




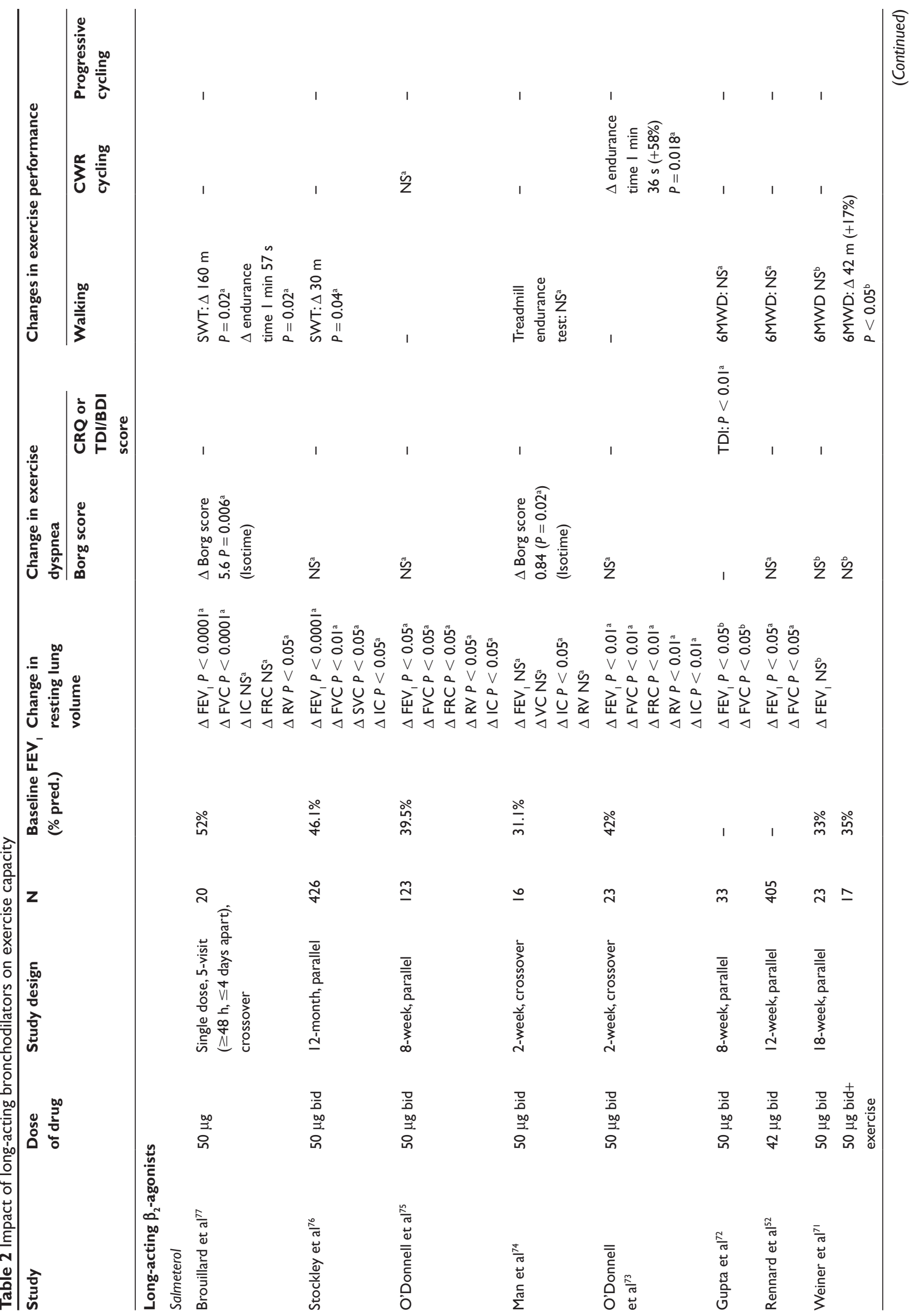




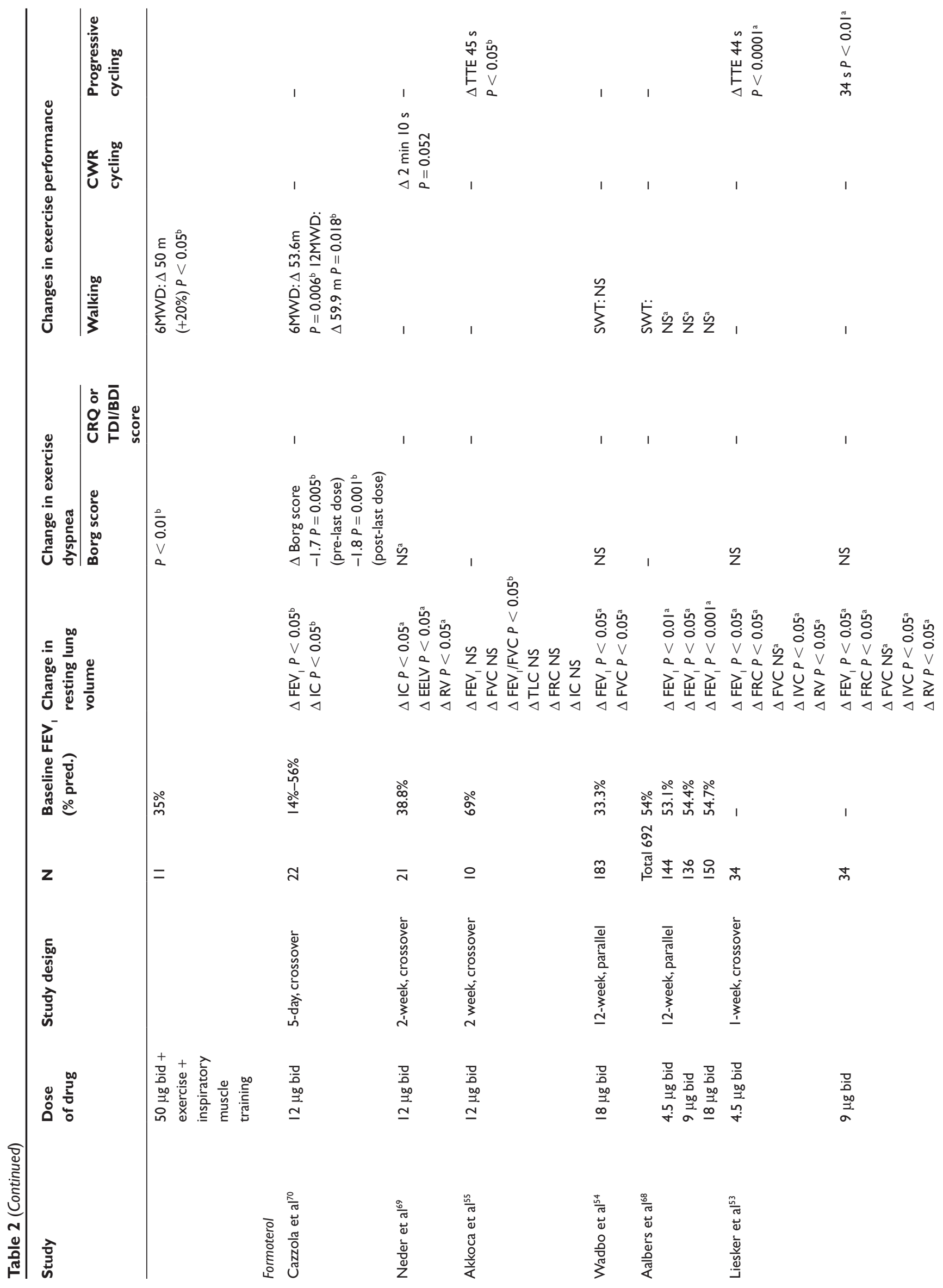




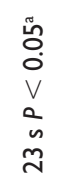
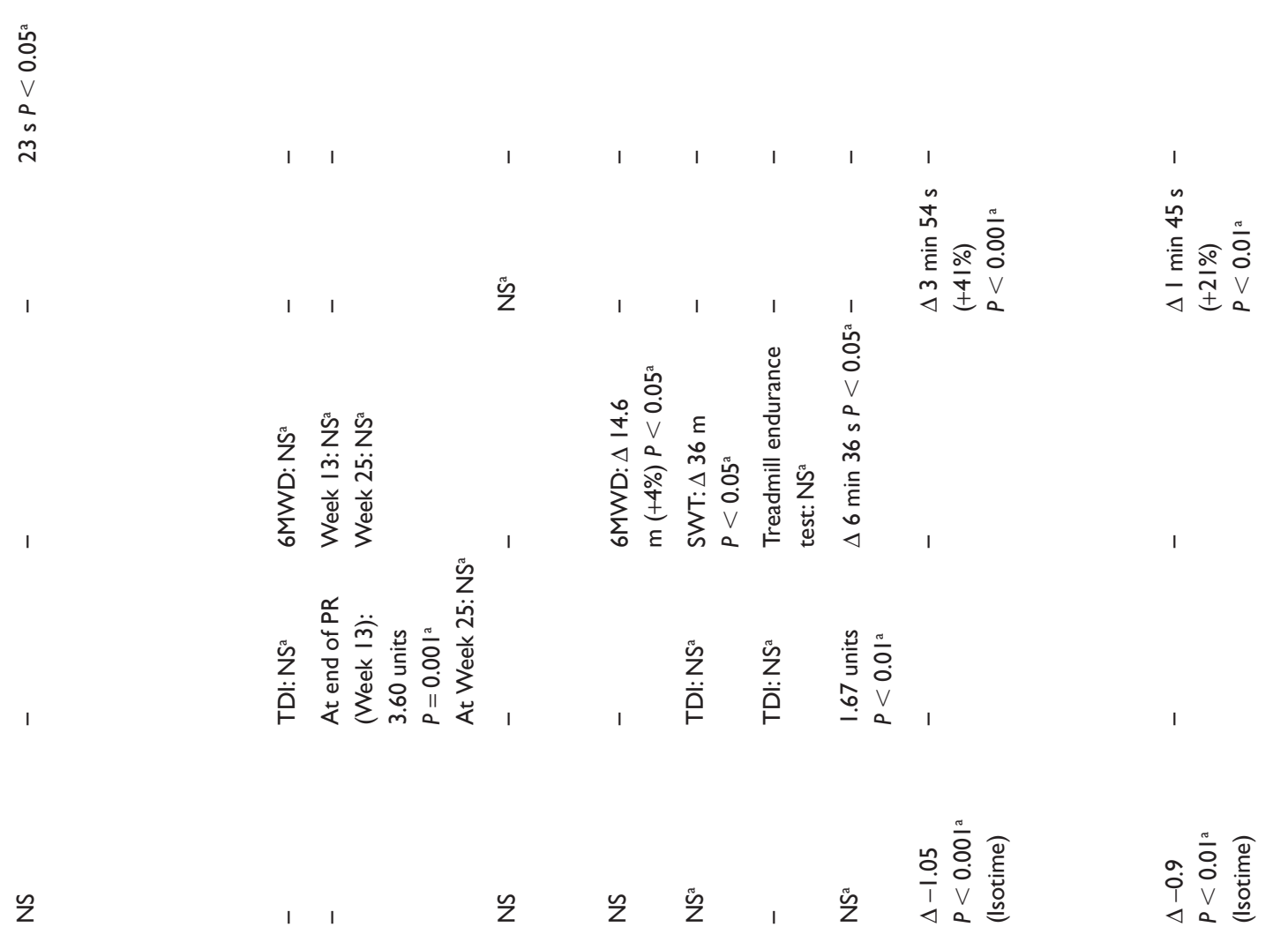

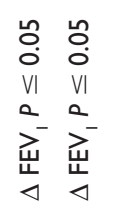

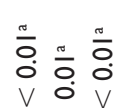

V $\begin{aligned} & 0.0 \\ & 0\end{aligned}$

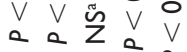

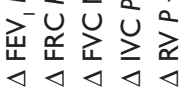

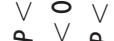

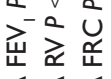

$\mathrm{V} \cap \mathrm{O}, \mathrm{V}$

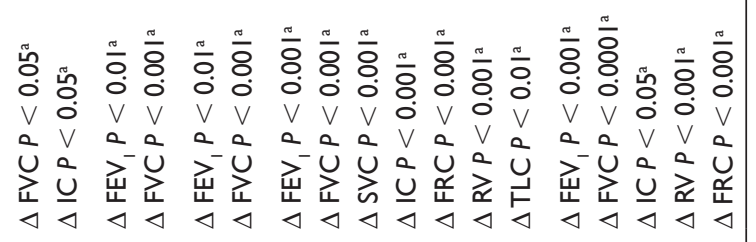

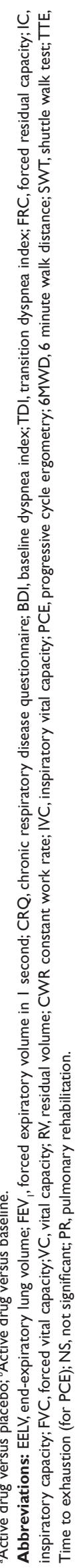

$\stackrel{\dot{m}}{2}$

ํํํ $\stackrel{\circ}{\text { ஸे }}$

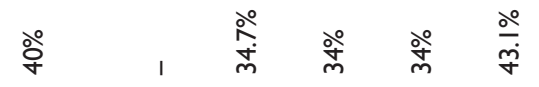

$\triangleq \triangleq$

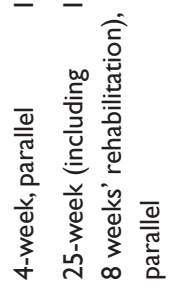

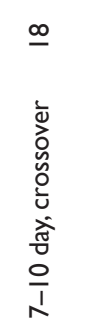

广 น นก นกำ

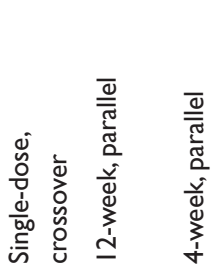

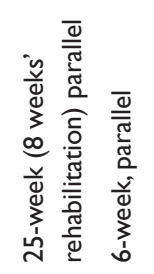

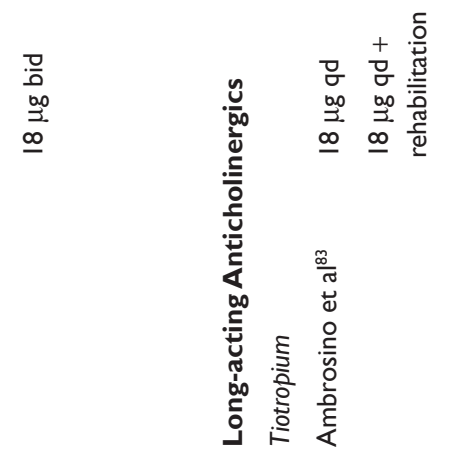

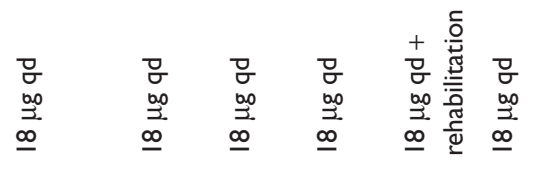

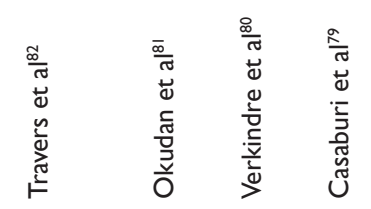

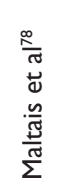

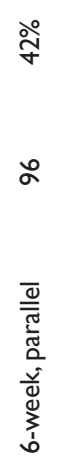

$\underset{\sigma}{\sigma}$
$\underline{00}$
$\underline{\Xi}$
$\underline{\infty}$

ঙे

ஃ

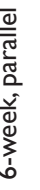




\section{Short-acting anticholinergics}

The effect of short-acting anticholinergics on exercise is inconsistent (Table 1). ${ }^{7,12,46,50,52-58}$ In general, they are recommended for the management of mild COPD and as required in symptomatic patients. ${ }^{10,59}$ Prior to the availability of the once-daily anticholinergic, tiotropium, short-acting anticholinergics had been used for chronic treatment across all severities of the disease.

Single doses of ipratropium have shown some beneficial effect on exercise tolerance. ${ }^{7,46,56}$ In many of the studies using 6MWD, including those reviewed by Liesker et al, ${ }^{11}$ the significant results did not reach the MCID proposed by Puhan and colleagues. ${ }^{28}$ MCID responses have been reported with the $\mathrm{SWT}^{56}$ and CWR cycling, ${ }^{12}$ though the latter did not achieve statistical significance, but did include study patients with more severe COPD than many of the other studies.

In longer-term studies involving treatment periods of up to 12 weeks, ${ }^{52-55}$ only Liesker et $\mathrm{al}^{53}$ and Akkoca et al ${ }^{55}$ found a significant improvement in exercise performance. Ipratropium significantly increased time to exhaustion in the incremental cycle exercise used by Liesker et $\mathrm{al}^{53}$ and Akkoca et al, ${ }^{55}$ though the latter small study was not statistically significant with respect to change in work rate.

Two studies examining the effect of oxitropium on exercise performance have been published since 1999..$^{50,58}$ Oga et $\mathrm{al}^{58}$ observed statistically significant (but not MCID) improvements in both the 6MWD ( $6 \mathrm{~m}$ increase, $P<0.05)$ and CWR cycle ergometry (34 s increased endurance, $P<0.001)$ compared with placebo, following a single dose of $400 \mu \mathrm{g}$ oxitropium. However, in the study by Shioya et al, ${ }^{50} 6 \mathrm{MWD}$ in patients receiving $600 \mu \mathrm{g}$ oxitropium was not shown to differ significantly from baseline after 12, 24 or 52 weeks of treatment. A total of six oxitropium studies ${ }^{60-65}$ were included in the review of Liesker et al, ${ }^{11}$ and in five of these studies ${ }^{60,62-65}$ a statistically significant improvement in exercise performance was observed, though these did not achieve a definite MCID.

In two single-dose studies ${ }^{66,67}$ evaluating the effect of a combination of salbutamol and ipratropium, improvements in endurance were observed, although statistical significance was only observed in that of Cukier et $\mathrm{al}^{66}$ who reported an improvement in 6MWD of $21 \mathrm{~m}(+6 \%, P<0.05)$ compared with placebo. In comparison, Peters et al ${ }^{67}$ reported that endurance time, using CWR cycle ergometry improved by $1 \mathrm{~min} 42 \mathrm{~s}(+31 \%)$ with a salbutamol-ipratropium combination, although this improvement failed to achieve statistical significance versus placebo $(P=0.067)$.

\section{Long-acting bronchodilators (Table 2)}

\section{Long-acting $\beta_{2}$-agonists}

The effects of two long-acting $\beta_{2}$-agonists on exercise capacity have been evaluated: formoterol ${ }^{53-55,68-70}$ and salmeterol $^{52,71-77}$ (Table 2).

In a study by Cazzola et al, ${ }^{70} 5$-day treatment with formoterol was shown to increase walking distance by $53.6 \mathrm{~m}$ at the end of the 6MWD test (achieving MCID) and by $59.9 \mathrm{~m}$ at the end of the 12MWD test compared with baseline. The perception of breathlessness measured by the Borg scale was also significantly reduced with formoterol compared with baseline. However, in two larger studies, ${ }^{54,68}$ formoterol treatment resulted in no significant improvement in the performance of the incremental SWT compared with placebo.

Using PCE to symptom limitation, Liesker et $\mathrm{al}^{53}$ showed significant enhancement of time to exhaustion after 1-week treatment with formoterol compared with placebo of between 23 and 44 seconds, as was reported in the previous review. Also using PCE, Akkoca et a ${ }^{55}$ demonstrated a significant improvement in time to exhaustion of 45 seconds compared with baseline after dosing with formoterol and following 14 days' treatment with formoterol. Using CWR cycling in patient with more severe COPD than in the previous two trials, change in endurance time with 2-week treatment with formoterol did not achieve statistical significance compared with placebo (Neder et al ${ }^{69}$ ).

For salmeterol, Liesker 2002 reviewed three studies performed before 2000, all of which did not find a significant effect of salmererol on walking distance (6MWD or 12MWD) after treatment for up to 12 weeks. ${ }^{11}$ Similar results have been found in three further studies using the 6MWD test since 2000 that are reported in Table 2, though the perception of dyspnea during exercise was significantly reduced in one of these studies. ${ }^{52,71,72}$ One study ${ }^{71}$ showed significant improvements in 6MWD with a combination of salmeterol and 6 weeks of general exercise training $(16 \%$ improvement; $P<0.05)$ or 6 weeks' general exercise training plus inspiratory muscle training $(20 \%$ improvement; $P<0.05)$. This may suggest an additive or synergistic effect of salmeterol and exercise training; however, this cannot be confirmed due to the study design.

Salmeterol has significantly improved exercise capacity measured using the SWT. ${ }^{76,77}$ In a large 1-year trial, patients treated with salmeterol walked a statistically significant 30 $\mathrm{m}$ further in an incremental SWT than patients treated with placebo, though the difference was below that considered clinically significant and perception of breathlessness was 
not statistically different. ${ }^{76}$ In a smaller, single-dose study, Brouillard et al ${ }^{77}$ demonstrated statistically significant improvements in walking performance with salmeterol compared with placebo measured by both incremental $(160 \mathrm{~m}$; $P<0.05)$ and endurance SWT $(1 \min 57 \mathrm{~s} ; P<0.05)$, with the difference in incremental SWT exceeding the MCID. Salmeterol also reduced the perception of dyspnea during exercise in this study when compared with placebo at an isotime, but not at the end of exercise.

O'Donnell et $\mathrm{al}^{73}$ demonstrated a clinically significant improvement of exercise endurance with 2-week treatment with salmeterol (1 $\mathrm{min} 36 \mathrm{~s}, 58 \%$ increase above placebo; $P<0.05)$ using a CWR cycle exercise test. This improvement in endurance time correlated with increases in IC, both at rest and during exercise, supporting the notion that hyperinflation has a major impact on exercise tolerance. However, a statistically significant difference from placebo was not observed in a later, larger CWR cycle exercise test trial following 8 -week treatment with salmeterol. ${ }^{75}$ Perception of dyspnea during exercise with salmeterol did not differ from placebo in either of these studies. A significant change in endurance time compared with placebo was also not seen following 2 weeks of treatment with salmeterol in a study using a CWR treadmill exercise test, ${ }^{74}$ though perception of dyspnea during exercise was reduced with salmeterol.

\section{Long-acting anticholinergic: tiotropium}

The once-daily anticholinergic, tiotropium, was first introduced for COPD in Europe in 2002 and has become one of the most prescribed maintenance treatments. Seven exercise studies with tiotropium have been published since 1999 and were not included in the previous systematic review (Table 3). ${ }^{18,78-83}$ As with other types of bronchodilators, ${ }^{13,73}$ tiotropium has shown reductions in parameters of hyperinflation, and improvements in exercise endurance time correlated with IC..$^{18,78,84}$

As observed with other bronchodilators, use of the 6MWD to investigate changes in exercise endurance with tiotropium has had limited success. ${ }^{81,83}$ A significant increase in the 6MWD $(P<0.05)$ was observed by Okudan et $\mathrm{al}^{81}$ following administration of a single dose of tiotropium compared with placebo, but this was below the MCID proposed by Puhan and colleagues and perception of dyspnea during exercise was not changed. ${ }^{28}$ However, no significant differences were observed in 6MWD or perception of dyspnea following 4-week treatment with tiotropium compared with placebo in a study that continued to investigate pulmonary rehabilitation. Compared with placebo, tiotropium significantly increased the mean distance walked during the SWT by $36 \mathrm{~m}(11.8 \%$ increase; $P<0.05$ ) after 12 weeks of treatment in the study by Verkindre et al. ${ }^{80}$ However, this too is below the MCID and perception of dyspnea was not different from placebo, despite a significant change in lung volumes.

Tiotropium has been reported to significantly increase CWR cycle endurance time compared with placebo by $1 \mathrm{~min} 45 \mathrm{~s}(21 \% \text { increase, } P<0.01)^{18}$ and by $3 \mathrm{~min} 54 \mathrm{~s}$ (41\% increase, $P<0.001)^{78}$ following 6 weeks of daily administration in two independent studies. The change in endurance time in the second of these studies exceeds the MCID proposed by Puente-Maestu and colleagues ${ }^{27}$ and perception of dyspnea during exercise was also significantly reduced by tiotropium in both trials. A statistically significant difference compared with placebo in CWR endurance time improvement and perception of dyspnea was not found in a smaller crossover trial by Travers et al. ${ }^{82}$

Casaburi et al demonstrated that tiotropium amplified the effects of pulmonary rehabilitation on CWR treadmill endurance, ${ }^{79}$ which has also been associated with an increase in self-reported participation in physical activity. ${ }^{85}$ Although 4-week treatment with tiotropium did not significantly increase endurance time alone compared with placebo (a difference of $1 \mathrm{~min} 39 \mathrm{~s} ; 15.6 \%$ increase), tiotropium significantly improved CWR treadmill endurance times compared with placebo following an 8-week pulmonary rehabilitation programme such that the difference between the groups was $6 \mathrm{~min} 36 \mathrm{~s}$ (41.9\% increase). In contrast, Ambrosino et $\mathrm{al}^{83}$ reported no improvement in 6MWD following the addition of tiotropium to pulmonary rehabilitation for 8 weeks, although significant improvements in dyspnea were observed compared with placebo $(P<0.01)$. These seemingly contradictory results may be reflective of the difference in sensitivity of the exercise tests used in these trials.

\section{Comparative studies (Table 3)}

Five studies ${ }^{46,52-55}$ directly evaluated the effects of different classes of bronchodilators (Table 3 ). Oga et $\mathrm{al}^{46}$ compared the effects of the short-acting $\beta_{2}$-agonist salbutamol with the short-acting anticholinergic ipratropium on exercise capacity using a CWR cycle ergometry test. Improvement in $\mathrm{FEV}_{1}$ was significantly greater with salbutamol compared with ipratropium, but the magnitudes of improvement in the CWR cycle ergometry test were similar with both treatments. Four studies ${ }^{52-55}$ compared the short-acting anticholinergic ipratropium with the long-acting $\beta_{2}$-agonists salmeterol ${ }^{52}$ or formoterol. ${ }^{53-55}$ No significant treatment differences between ipratropium and formoterol were observed in either the PCE 


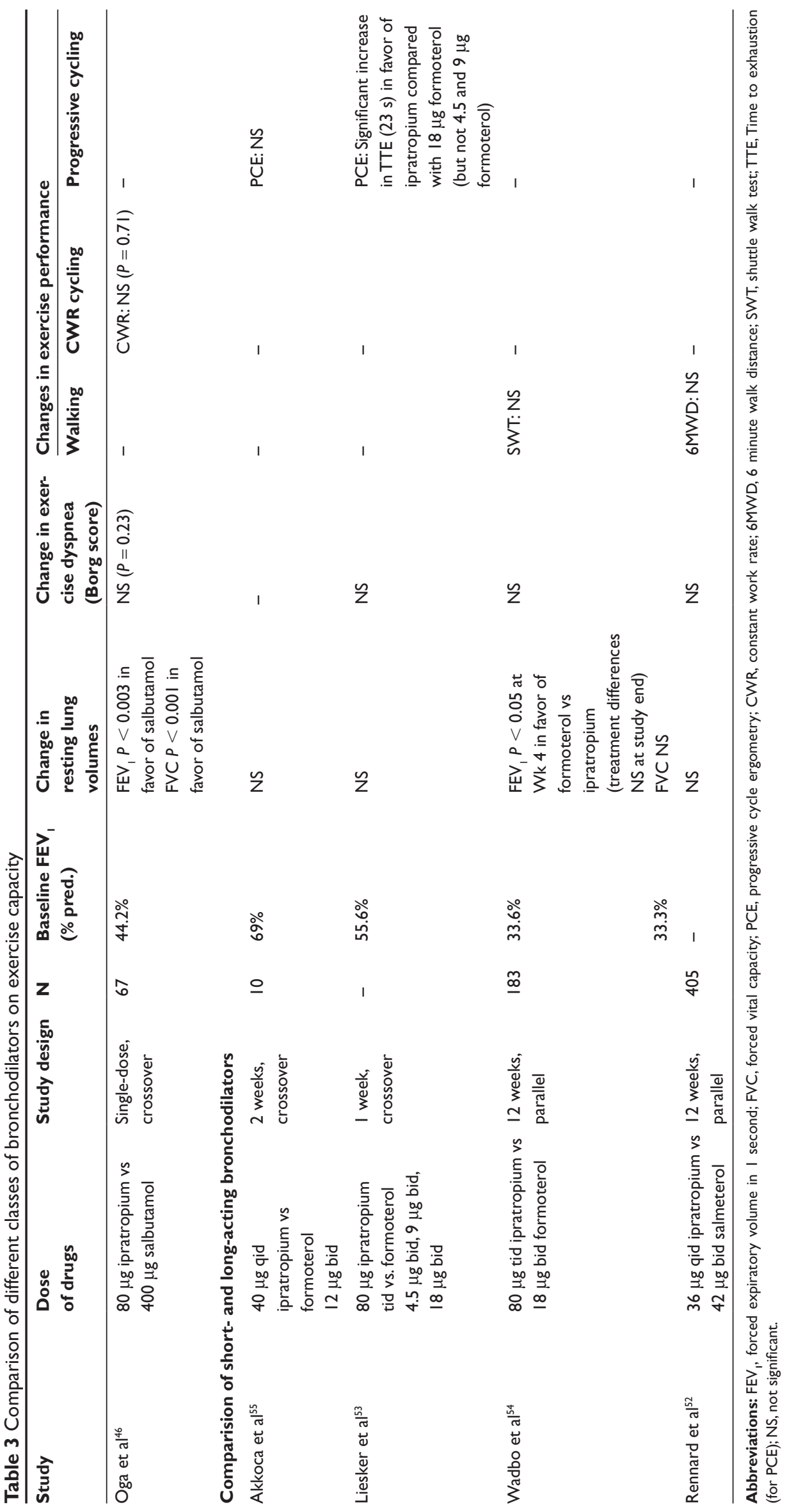


test performed by Akkoca et $\mathrm{al}^{55}$ or the SWT performed by Wadbo et al. ${ }^{54}$ A significant difference in favor of ipratropium compared with $18 \mu \mathrm{g}$ formoterol was found in time to exhaustion in the PCE test performed by Liesker et $\mathrm{al}^{53}$; however, no significant treatment difference was found between ipratropium and $4.5 \mu \mathrm{g}$ or $9 \mu \mathrm{g}$ formoterol. In the comparison between ipratropium and salmeterol by Oga et al, ${ }^{46}$ no significant difference between the two treatments was observed in terms of lung function, dyspnea or 6MWD.

As of yet, there are no published studies that have compared the effects on exercise capacity of long-acting $\beta_{2}$-agonists with the long-acting anticholinergic tiotropium.

\section{Conclusions}

Evidence for the efficacy of bronchodilators in enhancing the exercise capacity of patients with COPD is often contradictory. Some of the inconsistency may be explained by differences in the mode and duration of action of bronchodilators; however, considerable variations may be due to inherent differences in study design or patients studied. In particular, the method of assessing exercise tolerance is a matter for considerable discussion and requires further investigation before we can fully appreciate which bronchodilators consistently improve exercise endurance. However, some general points can be made from systematic review of the literature.

Short-acting bronchodilators may be an appropriate choice for additional bronchodilation when required, but are not suitable for use on a day-to-day basis to provide sustained bronchodilation and improve HRQoL. Important factors that contribute to HRQoL are enhanced symptom control and increased exercise capacity. For short-acting bronchodilators, the data suggest that their effects on exercise capacity are limited.

Longer-acting bronchodilators play an important role in the long-term management of patients with COPD, improving airflow limitation, reducing dyspnea linked to moderate exercise intensities, reducing exacerbation frequency, and improving HRQoL. Whether this generally leads to an increase in daily physical activities is currently unclear. Factors other than drug therapy alone are undoubtedly important in obtaining significantly improved exercise tolerance from bronchodilators.

The improvements in exercise tolerance and dyspnea observed under clinical trial conditions with some bronchodilators may impact on the everyday circumstances of COPD patients, reversing the vicious circle of chronic inactivity and muscle deconditioning, and leading to sustained improvements in HRQoL.

\section{Acknowledgments/disclosures}

Writing and editorial assistance was provided by David Macari, $\mathrm{PhD}$ and Claire Scarborough, PhD of PAREXEL MMS, which was contracted by Boehringer Ingelheim and Pfizer for these services. The author meets criteria for authorship as recommended by International Committee of Medical Journal Editors (ICMJE) and was fully responsible for all content and editorial decisions, and was involved at all stages of manuscript development. The author received no compensation related to the development of the manuscript.

\section{References}

1. Pauwels RA, Rabe KF. Burden and clinical features of chronic obstructive pulmonary disease (COPD). Lancet. 2004;364:613-620.

2. Doherty DE, Briggs DD Jr. Chronic obstructive pulmonary disease: epidemiology, pathogenesis, disease course, and prognosis. Clin Cornerstone. 2004;Suppl 2:S5-S16.

3. Mackay J, Amos A. Women and tobacco. Respirology. 2003;8: 123-130.

4. Zhang H, Cai B. The impact of tobacco on lung health in China Respirology. 2003;8:17-21.

5. Oga T, Nishimura K, Tsukino M, Sato S, Hajiro T. Analysis of the factors related to mortality in chronic obstructive pulmonary disease: role of exercise capacity and health status. Am J Respir Crit Care Med. 2003;167:544-549.

6. Martinez FJ, Foster G, Curtis JL, Criner G, Weinmann G, Fishman A, et al. Predictors of mortality in patients with emphysema and severe airflow obstruction. Am J Respir Crit Care Med. 2006;173:1326-1334.

7. Pepin V, Saey D, Whittom F, LeBlanc P, Maltais F. Walking versus cycling: sensitivity to bronchodilation in chronic obstructive pulmonary disease. Am J Respir Crit Care Med. 2005;172:1517-1522.

8. Aguilaniu B, Plaindoux A, Brosson C, Jeanmart M, Maitre J, Diab S. Dyspnea and handicap in chronic obstructive pulmonary disease: interaction of their mechanisms. Presse Med. 2009;38:413-420.

9. Ferguson GT. Recommendations for the management of COPD. Chest. 2000;117:23S-28S.

10. Global Initiative for Chronic Obstructive Lung Disease. Global strategy for the diagnosis, management, and prevention of chronic obstructive pulmonary disease. www.goldcopd.com. Accessed 12 Jan, 2009.

11. Liesker JJW, Wijkstra PJ, Ten Hacken NHT, Koeter GH, Postma DS, Kerstjens HAM. A systematic review of the effects of bronchodilators on exercise capacity in patients with COPD. Chest. 2002;121:597-608.

12. Saey D, Debigare R, LeBlanc P, Mador MJ, Cote CH, Jobin J, et al. Contractile leg fatigue after cycle exercise: a factor limiting exercise in patients with chronic obstructive pulmonary disease. Am J Respir Crit Care Med. 2003;168:425-430.

13. O’Donnell DE, Lam MIU, Webb KA. Spirometric correlates of improvement in exercise performance after anticholinergic therapy in chronic obstructive pulmonary disease. Am J Respir Crit Care Med. 1999;160:542-549.

14. O’Donnell DE, Lam MIU, Webb KA. Measurement of symptoms, lung hyperinflation, and endurance during exercise in chronic obstructive pulmonary disease. Am J Respir Crit Care Med. 1998;158:1557-1565.

15. Pitta F, Takaki MY, Oliveira NH, Sant'anna TJ, Fontana AD, Kovelis D, et al. Relationship between pulmonary function and physical activity in daily life in patients with COPD. Respir Med. 2008;102:1203-1207.

16. O'Donnell DE. Ventilatory limitations in chronic obstructive pulmonary disease. Med Sci Sports Exerc. 2001;33:S647-S655.

17. Marin JM, Carrizo SJ, Gascon M, Sanchez A, Gallego B, Celli BR. Inspiratory capacity, dynamic hyperinflation, breathlessness, and exercise performance during the 6-minute-walk test in chronic obstructive pulmonary disease. Am J Respir Crit Care Med. 2001;163:1395-1399. 
18. O’Donnell DE, Flüge T, Gerken F, Hamilton A, Webb K, Aguilaniu B, et al. Effects of tiotropium on lung hyperinflation, dyspnea and exercise tolerance in patients with COPD. Eur Respir J. 2004;23:832-840.

19. Killian KJ. Limitation to muscular activity in chronic obstructive pulmonary disease. Eur Respir J. 2004;24:6-7.

20. Harver A, Schwartzstein RM, Killian KJ, Mahler DA, O’Donnell DE, Serby CW, et al. Understanding dyspnoea in COPD: mechanisms, measurement and management. Eur Respir Rev. 2002;12:25-55.

21. Rennard S, Decramer M, Calverley PMA, Pride NB, Soriano JB, Vermiere PA, et al. Impact of COPD in North America and Europe in 2000: subjects' perspective of Confronting COPD International Survey. Eur Respir J. 2002;20:799-805.

22. Kline Leidy N. Functional performance in people with chronic obstructive pulmonary disease. Image J Nurs Sch. 1995;27:23-34.

23. ATS/ACCP Statement on cardiopulmonary exercise testing. Am J Respir Crit Care Med. 2003;167:211-277.

24. Beck KC, Weisman IM. Methods for cardiopulmonary exercise testing. In: Weisman IM, Zeballos RJ, editors. Clinical Exercise Testing. Basel: Karger; 2002. p. 43-59.

25. Murray JA, Waterman LA, Ward J, Baird JC, Mahler DA. Perceptual and physiologic responses during treadmill and cycle exercise in patients with COPD. Chest. 2009;135:384-390.

26. Lacasse Y, Wong E, Guyatt GH, King D, Cook DJ, Goldstein RS. Metaanalysis of respiratory rehabilitation in chronic obstructive pulmonary diseases. Lancet. 1996;348:1115-1119.

27. Puente-Maestu L, Villar F, de Miguel J, Stringer WW, Sanz P, Sanz ML, et al. Clinical relevance of constant power exercise duration changes in COPD. Eur Respir J. 2009;34:340-345.

28. Puhan MA, Mador MJ, Held U, Goldstein R, Guyatt GH, Schunemann HJ. Interpretation of treatment changes in 6-minute walk distance in patients with COPD. Eur Respir J. 2008;32:637-643.

29. ATS statement: guidelines for the six-minute walk test. Am J Respir Crit Care Med. 2002;166:111-117.

30. Redelmeier DA, Bayoumi AM, Goldstein RS, Guyatt GH. Interpreting small differences in functional status: the Six Minute Walk test in chronic lung disease patients. Am J Respir Crit Care Med. 1997; 155:1278-1282.

31. Singh SJ, Morgan MD, Scott S, Walters D, Hardman AE. Development of a shuttle walking test of disability in patients with chronic airways obstruction. Thorax. 1992;47:1019-1024.

32. Singh SJ, Jones PW, Evans R, Morgan MD. Minimum clinically important improvement for the incremental shuttle walking test. Thorax. 2008;63:775-777.

33. Dreher M, Walterspacher S, Sonntag F, Prettin S, Kabitz HJ, Windisch W. Exercise in severe COPD: is walking different from stair-climbing? Respir Med. 2008;102:912-918.

34. Skumlien S, Hagelund T, Bjortuft O, Ryg MS. A field test of functional status as performance of activities of daily living in COPD patients. Respir Med. 2006;100:316-323.

35. Zhan S, Cerny FJ, Gibbons WJ, Mador MJ, Wu YW. Development of an unsupported arm exercise test in patients with chronic obstructive pulmonary disease. J Cardiopulm Rehabil. 2006;26:180-187.

36. Dechman G, Scherer S. Outcome measures in cardiopulmonary physical therapy: Focus on the Glittre ADL test for people with chronic obstructive pulmonary disease. Cardiopulmonary Physical Therapy Journal. 2008; 19:115-118.

37. Ozalevli S, Ozden A, Itil O, Akkoclu A. Comparison of the Sit-to-Stand Test with 6 min walk test in patients with chronic obstructive pulmonary disease. Respir Med. 2007;101:286-293.

38. Hill CJ, Denehy L, Holland AE, McDonald CF. Measurement of functional activity in chronic obstructive pulmonary disease: the grocery shelving task. J Cardiopulm Rehabil Prev. 2008;28:402-409.

39. Leitch AG, Hopkin JM, Ellis DA, Merchant S, McHardy GJ. The effect of aerosol ipratropium bromide and salbutamol on exercise tolerance in chronic bronchitis. Thorax. 1978;33:711-713.

40. Leitch AG, Morgan A, Ellis DA, Bell G, Haslett C, McHardy GJ. Effect of oral salbutamol and slow-release aminophylline on exercise tolerance in chronic bronchitis. Thorax. 1981;36:787-789.
41. Shah SS, Johnston D, Woodcock AA, Johnson M, Geddes DM. Breathlessness and exercise tolerance in chronic airflow obstruction: 2-hourly versus 4-hourly salbutamol by inhalation. Curr Med Res Opin. 1983;8:345-349.

42. Corris PA, Neville E, Nariman S, Gibson GJ. Dose-response study of inhaled salbutamol powder in chronic airflow obstruction. Thorax. 1983;38:292-296.

43. Connolly CK, Chan NS. Salbutamol and ipratropium in partially reversible airway obstruction. Br J Dis Chest. 1987;81:55-61.

44. Mohammed AF, Anderson K, Matusiewicz SP, Boyd G, Greening AP, Thomson NC. Effect of controlled-release salbutamol in predominantly non-reversible chronic airflow obstruction. Respir Med. 1991;85: 495-500.

45. Blosser SA, Maxwell SL, Reeves-Hoche MK, Russell Localio A, Zwillich CW. Is an anticholinergic agent superior to a $\beta_{2}$-agonist in improving dyspnea and exercise limitation in COPD? Chest. 1995; 108:730-735.

46. Oga T, Nishimura K, Tsukino M, Sato S, Hajiro T, Mishima M. A comparison of the effects of salbutamol and ipratropium bromide on exercise endurance in patients with COPD. Chest. 2003;123:1810-1816.

47. Aliverti A, Rodger K, Dellacà RL, Stevenson N, Lo MA, Pedotti A, et al. Effect of salbutamol on lung function and chest wall volumes at rest and during exercise in COPD. Thorax. 2005;60:916-924.

48. Porto EF, Castro AAM, Nascimento O, Oliveira RC, Cardoso F, Jardim JR. Modulation of operational lung volumes with the use of salbutamol in COPD patients accomplishing upper limbs exercise tests. Respir Med. 2009;103:251-257.

49. Walters EH, Walters J. Inhaled short acting beta2-agonist use in asthma: regular vs as needed treatment. Cochrane Database Syst Rev. 2000: CD001285.

50. Shioya T, Satake M, Sato K, Sano MA, Sugawara K, Takahashi H, et al. Long-term effect of the beta2-receptor agonist procaterol on daily life performance and exercise capacity in patients with stable chronic obstructive pulmonary disease. Clinical study with special reference to health-related quality of life and activities of daily living. Arzneimittelforschung. 2008;58:24-28.

51. Sukisaki T, Senjyu H, Oishi K, Rikitomi N, Ariyoshi K. Single dose of inhaled procaterol has a prolonged effect on exercise performance of patients with COPD. Physiother Theory Pract. 2008;24:255-263.

52. Rennard SI, Anderson W, ZuWallack R, Broughton J, Bailey W, Friedman $\mathrm{M}$, et al. Use of a long-acting inhaled $\beta_{2}$-adrenergic agonist, salmeterol xinafoate, in patients with chronic obstructive pulmonary disease. Am J Respir Crit Care Med. 2001;163:1087-1092.

53. Liesker JJ, Van De Velde V, Meysman M, Vincken W, Wollmer P, Hansson L, et al. Effects of formoterol (Oxis Turbuhaler) and ipratropium on exercise capacity in patients with COPD. Respir Med. 2002;96: 559-566.

54. Wadbo M, Löfdahl CG, Larsson K, Skoogh BE, Tornling G, Arweström E, et al. Effects of formoterol and ipratropium bromide in COPD: a 3-month placebo-controlled study. Eur Respir J. 2002;20: $1138-1146$.

55. Akkoca YO, Onen ZP, Demir G, Eris GB, Saryal S, Karabiyikoglu G. Is there any difference between effects of ipratropium bromide and formoterol on exercise capacity in moderate COPD patients? Tuberk Toraks. 2006;54:105-113.

56. Pepin V, Brodeur J, Lacasse Y, Milot J, LeBlanc P, Whittom F, et al. Six-minute walking versus shuttle walking: responsiveness to bronchodilation in chronic obstructive pulmonary disease. Thorax. 2007;62:291-298.

57. O’Donnell DE, Laveneziana P, Ora J, Webb KA, Lam YM, Ofir D. Evaluation of acute bronchodilator reversibility in patients with symptoms of GOLD stage I COPD. Thorax. 2009;64:216-223.

58. Oga T, Nishimura K, Tsukino M, Hajiro T, Ikeda A, Izumi T. The effects of oxitropium bromide on exercise performance in patients with stable chronic obstructive pulmonary disease. A comparison of three different exercise tests. Am J Respir Crit Care Med. 2000;161:1897-1901.

59. Weder MM, Donohue JF. Role of bronchodilators in chronic obstructive pulmonary disease. Semin Respir Crit Care Med. 2005;26:221-234. 
60. Hay JG, Stone P, Carter J, Church S, Ey-Brook A, Pearson MG, et al. Bronchodilator reversibility, exercise performance and breathlessness in stable chronic obstructive pulmonary disease. Eur Respir J. 1992;5:659-664.

61. Teramoto S, Fukuchi Y, Orimo H. Effects of inhaled anticholinergic drug on dyspnea and gas exchange during exercise in patients with chronic obstructive pulmonary disease. Chest. 1993;103:1774-1782.

62. Spence DP, Hay JG, Carter J, Pearson MG, Calverley PM. Oxygen desaturation and breathlessness during corridor walking in chronic obstructive pulmonary disease: effect of oxitropium bromide. Thorax. 1993;48:1145-1150.

63. Ikeda A, Nishimura K, Koyama H, Sugiura N, Izumi T. Oxitropium bromide improves exercise performance in patients with COPD. Chest. 1994;106:1740-1745.

64. Teramoto S, Fukuchi Y. Improvements in exercise capacity and dyspnoea by inhaled anticholinergic drug in elderly patients with chronic obstructive pulmonary disease. Age Ageing. 1995;24:278-282.

65. Teramoto S, Matsuse T, Sudo E, Ohga E, Katayama H, Suzuki M, et al Long-term effects of inhaled anticholinergic drug on lung function, dyspnea, and exercise capacity in patients with chronic obstructive pulmonary disease. Intern Med. 1996;35:772-778.

66. Cukier A, Ferreira CA, Stelmach R, Ribeiro M, Cortopassi F, Calverley PM. The effect of bronchodilators and oxygen alone and in combination on self-paced exercise performance in stable COPD. Respir Med. 2007;101:746-753.

67. Peters MM, Webb KA, O’Donnell DE. Combined physiological effects of bronchodilators and hyperoxia on exertional dyspnoea in normoxic COPD. Thorax. 2006;61:559-567.

68. Aalbers R, Ayres J, Backer V, Decramer M, Lier PA, Magyar P, et al. Formoterol in patients with chronic obstructive pulmonary disease: a randomized, controlled, 3-month trial. Eur Respir J. 2002;19:936-943.

69. Neder JA, Fuld JP, Overend T, Thirlwell J, Carter R, Stevenson R, et al. Effects of formoterol on exercise tolerance in severely disabled patients with COPD. Respir Med. 2007;101:2056-2064.

70. Cazzola M, Biscione GL, Pasqua F, Crigna G, Appodia M, Cardaci V, et al. Use of 6-min and 12-min walking test for assessing the efficacy of formoterol in COPD. Respir Med. 2008;102:1425-1430.

71. Weiner P, Magadle R, Berar-Yanay N, Davidovich A, Weiner M. The cumulative effect of long-acting bronchodilators, exercise, and inspiratory muscle training on the perception of dyspnea in patients with advanced COPD. Chest. 2000;118:672-678.

72. Gupta RK, Chhabra SK. An evaluation of salmeterol in the treatment of chronic obstructive pulmonary diseases. Indian J Chest Dis Allied Sci. 2002;44:165-172.
73. O'Donnell DE, Voduc N, Fitzpatrick M, Webb KA. Effect of salmeterol on the ventilatory response to exercise in chronic obstructive pulmonary disease. Eur Respir J. 2004;24:86-94.

74. Man WDC, Mustfa N, Nikoletou D, Kaul S, Hart N, Rafferty GF, et al. Effect of salmeterol on respiratory muscle activity during exercise in poorly reversible COPD. Thorax. 2004;59:471-476.

75. O’Donnell DE, Sciurba F, Celli B, Mahler DA, Webb KA, Kalberg CJ, et al. Effect of fluticasone propionate/salmeterol on lung hyperinflation and exercise endurance in COPD. Chest. 2006;130:647-656.

76. Stockley RA, Chopra N, Rice L. Addition of salmeterol to existing treatment in patients with COPD: a 12 month study. Thorax. 2006;61:122-128.

77. Brouillard C, Pepin V, Milot J, Lacasse Y, Maltais F. Endurance shuttle walking test: responsiveness to salmeterol in COPD. Eur Respir J. 2008;31:579-584.

78. Maltais F, Hamilton A, Marciniuk D, Hernandez P, Sciurba FC, Richter K, et al. Improvements in symptom-limited exercise performance over $8 \mathrm{~h}$ with once-daily tiotropium in patients with COPD. Chest. 2005;128:1168-1178.

79. Casaburi R, Kukafka D, Cooper CB, Witek TJ Jr, Kesten S. Improvement in exercise tolerance with the combination of tiotropium and pulmonary rehabilitation in patients with COPD. Chest. 2005;127:809-817.

80. Verkindre C, Bart F, Aguilaniu B, Fortin F, Guerin JC, Le Merre C, et al. The effect of tiotropium on hyperinflation and exercise capacity in chronic obstructive pulmonary disease. Respiration. 2006;73: $420-427$.

81. Okudan N, Gok M, Gokbel H, Suerdem M. Single dose of tiotropium improves the 6-minute walk distance in chronic obstructive pulmonary disease. Lung. 2006;184:201-204.

82. Travers J, Laveneziana P, Webb KA, Kesten S, O’Donnell DE. Effect of tiotropium bromide on the cardiovascular response to exercise in COPD. Respir Med. 2007;101:2017-2024.

83. Ambrosino N, Foglio K, Balzano G, Paggiaro PL, Lessi P, Kesten S. Tiotropium and exercise training in COPD patients: effects on dyspnea and exercise tolerance. Int J Chron Obstruct Pulmon Dis. 2008;3: 771-780.

84. Celli B, ZuWallack R, Wang S, Kesten S. Improvement in resting inspiratory capacity and hyperinflation with tiotropium in COPD patients with increased static lung volumes. Chest. 2003;124:1743-1748.

85. Kesten S, Casaburi R, Kukafka D, Cooper CB. Improvement in selfreported exercise participation with the combination of tiotropium and rehabilitative exercise training in COPD patients. Int J Chron Obstruct Pulmon Dis. 2008;3:127-136.
International Journal of COPD

\section{Publish your work in this journal}

The International Journal of COPD is an international, peer-reviewed journal of therapeutics and pharmacology focusing on concise rapid reporting of clinical studies and reviews in COPD. Special focus is given to the pathophysiological processes underlying the disease, intervention programs, patient focused education, and self management protocols.

\section{Dovepress}

This journal is indexed on PubMed Central, MedLine and CAS. The manuscript management system is completely online and includes a very quick and fair peer-review system, which is all easy to use. Visi http://www.dovepress.com/testimonials.php to read real quotes from published authors. 